\title{
BMJ Open Measuring shared decision-making and collaborative goal setting in community rehabilitation: a focused ethnography using cross-sectional surveys in Canada
}

\author{
Kiran Pohar Manhas (D , ${ }^{1}$ Karin Olson, ${ }^{2}$ Katie Churchill, ${ }^{3}$ Peter Faris, ${ }^{4}$ \\ Sunita Vohra, ${ }^{5}$ Tracy Wasylak ${ }^{1}$
}

To cite: Manhas KP, Olson K, Churchill $\mathrm{K}$, et al. Measuring shared decision-making and collaborative goal setting in community rehabilitation: a focused ethnography using cross-sectional surveys in Canada. BMJ Open 2020;10:e034745. doi:10.1136/ bmjopen-2019-034745

- Prepublication history for this paper is available online. To view these files, please visit the journal online (http://dx.doi org/10.1136/bmjopen-2019034745).

Received 04 0ctober 2019 Revised 04 June 2020 Accepted 13 July 2020

Check for updates

(c) Author(s) (or their employer(s)) 2020. Re-use permitted under CC BY-NC. No commercial re-use. See rights and permissions. Published by BMJ.

${ }^{1}$ Strategic Clinical Networks, Alberta Health Services, Calgary, Alberta, Canada

${ }^{2}$ Faculty of Nursing, University of Alberta, Edmonton, Alberta, Canada

${ }^{3}$ Health Professions, Strategy \& Practice, Alberta Health Services, Calgary, Alberta,

Canada

${ }^{4}$ Analytics (DIMR), Health Services Statistical \& Analytic Methods, Alberta Health

Services, Calgary, Alberta,

Canada

${ }^{5}$ Pediatrics, University of Alberta, Edmonton, Alberta, Canada

Correspondence to

Dr Kiran Pohar Manhas;

kiran.poharmanhas@ahs.ca

\section{ABSTRACT}

Objective To describe and measure the shared decision-making (SDM) experience, including goalsetting experiences, from the perspective of patients and providers in diverse community-rehabilitation settings. Design Prospective, Iongitudinal surveys.

Setting 13 primary level-of-care community-rehabilitation sites in diverse areas varying in geography, patient population and provider discipline

341 adult, English-speaking patient-participants, and 66 provider-participants.

Measures Alberta Shared decision-maKing Measurement Instrument (dyadic tool measuring SDM), WatLX (outpatient rehabilitation experience) and demographic questionnaire. Survey packages distributed at two timepoints

( $\mathrm{T} 0=$ recruitment; $\mathrm{T} 1=3$ months later).

Results We found that among 341 patient-provider dyads, $26.4 \%$ agreed that the appointment at recruitment involved high-quality SDM. Patient perceptions of goalsetting suggested that $19.6 \%$ of patients did not set a goal for their care, and only $11.4 \%$ set goals in functional language that tied directly to an activity/role/responsibility that was meaningful to their life. Better SDM was clinically associated with higher total family income $(p=0.045)$. Conclusions These findings provide evidence for the importance of SDM and goal setting in community rehabilitation. Among patients, lower ratings of SDM corresponded with less recognition of their preferences. Actionable strategies include supporting financially vulnerable patients in realising SDM through training of providers to make extra space for such patients to share their preferences and better preparing patients to articulate their preferences. We recommend more research into strategies that advance highly functional goal setting with patients, and that lessen survey ceiling effects.

\section{INTRODUCTION}

Many public policies aim to better empower patients in their health and healthcare. ${ }^{1-7}$ Patient-centred care, which emphasises shared decision-making (SDM) and patient engagement, is one strategy to empower patients. ${ }^{5} \mathrm{SDM}$ is an interpersonal decisionmaking process where provider(s) and
Strengths and limitations of the study

- One strength is that this study has a significant sample size, with 341 patient participants completing surveys.

- Another strength is that participant diversity allows for statistically appropriate comparisons based on geography, level of privacy, patient demographics and provider training.

- Study limitations include that the survey measuring shared decision-making is novel, has a floor effect and may be subject to acquiescence and social desirability biases.

patient make treatment choices collaboratively using best available evidence, patient values and preferences. ${ }^{89}$

SDM meets an ethical imperative to enable patient autonomy. ${ }^{10}{ }^{11}$ Research suggests that SDM increases patient knowledge and satisfaction, ${ }^{12-14}$ enhances realisation of treatment goals, ${ }^{15}$ moderately reduces inappropriate service utilisation ${ }^{16}$ and improves patientreported outcomes. ${ }^{12} 17$ SDM is neither routinely used nor taught in healthcare..$^{11} 1819$

SDM is multifaceted..$^{20}$ Based on a systematic review ( $\mathrm{n}=418$ studies), Makoul and Clayman $^{20}$ describe an SDM model with nine essential elements: problem definition; presenting and discussing options; discussing patient values and abilities; discussing provider knowledge; clarifying understanding; decision-making; and arranging follow-up. This SDM model overlaps with conceptualisations, and practices, of collaborative goal setting in rehabilitation. ${ }^{21} 22$

SDM literature emphasises patient-physician interactions. Less research examines the impacts of SDM on other professionals, teams and organisations ${ }^{10}$; on the appropriate policy types for building SDM capacity within organisations ${ }^{9}$; and on SDM in rehabilitation 
involving primarily allied-health providers. ${ }^{21}$ Authors of a narrative synthesis ( $\mathrm{n}=15$ studies) revealed that in-patient rehabilitation goal setting did not permit patient input, was overly controlled by staff and involved parties lacking knowledge about SDM. ${ }^{21}$ Five further studies evaluated a 'train-the-trainer' programme to promote SDM in inpatient rehabilitation using focus groups, surveys and a cluster-randomised controlled study, but did not fully elaborate the SDM experience in rehabilitation. ${ }^{23-27}$ Other research theorises on SDM in rehabilitation, positing on technology, ethics and collaboration. ${ }^{28-32}$ The transferability of these findings to community contexts is unclear. ${ }^{21}$ Inpatient and outpatient needs and resources vary, impacting communication and care..$^{33} 34$

The measurement of SDM-related constructs remains challenging. ${ }^{35-37}$ A plethora of SDM definitions contributed to many different SDM measurement tools being developed. ${ }^{35} 38 \quad 39$ No universally accepted standard outcome or experience measure exists to assess SDM, ${ }^{35}$ particularly for non-physician interactions. A 2015 review found that only 4 of 13 SDM tools involved patients during their development, ${ }^{37}$ bringing into question content validity. Potentially inaccurate presumptions remain that patients are aware of 'decision points' and that only one decision point exists per consult. ${ }^{37}$

While the Option Grid ${ }^{\mathrm{TM}}$ is a commonly used tool to measure SDM, ${ }^{40}{ }^{41}$ its use of a third-party observer is not universally feasible in resource-constrained healthcare settings (as in our study context). Qualitative research by team members revealed challenges with a previously published SDM tool (SDM-Q-9) in primary care and mental health settings. ${ }^{42}$ Challenges included inability to capture the SDM phase when problems are discussed and prioritised; the lack of a 'not applicable' option; an overemphasis on medical conditions; a lack of relevance for non-pharmacological interventions; and the lack of recognition that SDM is valuable in goal setting, investigations, as well as (as opposed to exclusively for) exploring treatment options. ${ }^{43}$

In this context, the provincial health system sought to understand the experience of SDM and collaborative goal setting at diverse community rehabilitation sites across the province. This health system is the longest running provincial health system in Canada and serves more than 4 million people. This work would form the baseline data to eventually evaluate the implementation of a novel model of care seeking to promote patient-centred care and collaborative goal setting in community rehabilitation. In this study, for patients and providers of diverse community-rehabilitation sites across a single province in an industrialised country, we aimed to:

1. Measure the prevalence of high-quality SDM experiences (compared with less than high quality SDM experiences).

2. Measure goal-setting perceptions by patients.

3. Determine any associations between SDM experience or goal-setting perceptions and demographic and contextual factors (eg, geography, patient and provider age, gender, discipline).

This study included a small pilot feasibility study in this population to understand the reliability of the SDM tool and recruitment logistics. This study complements another in this population that used qualitative interviews to explore SDM experiences. ${ }^{42}$ The research team included two patient-coinvestigators who consulted on the research design, implementation and results dissemination.

\section{METHODS}

We used focused ethnography in this research programme. ${ }^{44}$ Ethnography involves making cultural inferences '(1) from what people say; (2) from the way people act; and (3) from the artefacts people use'. ${ }^{45}$ We focused on the communities of patients and professionals composing diverse community-rehabilitation sites across a provincial geography. Focused ethnography features a problem-focused and context-specific approach; a focus on a discrete phenomenon; the conceptual orientation of a single researcher; involvement of limited participants; episodic participant observation; participants with specific knowledge; and an emphasis on academic and healthcare settings. ${ }^{46}$ We met all criteria save participant observation due to feasibility constraints. While this paper emphasises the survey findings, this paper is part of a broader study that included qualitative interviews, focus groups and patient-led data collection. ${ }^{42}$ Together, this research programme followed an ethnographic methodology that underpinned its theoretical approach to data collection and analysis, which carried into this survey work equally. The surveys allowed a population-level perspective to inform the in-depth qualitative work. ${ }^{43}$

\section{Participant population}

We captured diverse rehabilitation settings that saw outpatients including both public and private provider sites, as well as three geographical types (rural (population $<10000$ ), regional-urban (population between 10000 and 100000 ) and metropolitan-urban (where population $>100000)$ ).

Participants included current patients and providers visiting and working, respectively, at study sites. Provider inclusion criterion was employment at the site at recruitment. Providers included allied-health professionals who were members of the rehabilitation team (eg, physical therapists, occupational therapists, speech-language pathologists). Patient inclusion criteria included $\geq 18$ years of age; their provider was participating; able to consent without proxy; and can understand and speak English. There were no exclusion criteria.

\section{Recruitment}

Site leadership informed provider recruitment. Tactics included email introductions followed by study 
presentations (by webinar, in person, or one on one). After discussions, informed consent was procured.

Convenience sampling directed patient recruitment. Management identified onsite recruiters from clerical and therapy-assistant staff. Researchers trained recruiters to identify eligible patients, discuss participation and record those patients accepting take-home study packages. While provider-participants may have mentioned the study to patients, only onsite recruiters distributed surveys. Recruitment was bounded by a 4-week site maximum and a 20-patient limit per provider to minimise site and provider burden. Patient consent was implied by the mailed return of surveys; written consent was required for future data sharing and future research contact.

\section{Data collection}

We used validated surveys to measure SDM, goal setting, quality of life and patient experience: at baseline (T0), we captured SDM (Alberta Shared decision-maKing Measurement Instrument (ASK-MI) tool), perceptions on goal setting, quality of life, demographic and contextual data; at 3 months post baseline (T1), we captured quality of life and overall patient-reported rehabilitation experience (WatLX survey). The patient demographic and contextual data captured self-reported age, gender, education, income, medical conditions and their perceptions of their health journey (ie, where they were in their rehabilitation, whether they perceived a goal was set for their rehabilitation, and if so what that goal was). The provider demographic and contextual data included selfreported age, gender, professional discipline and years of experience. Providers were also asked if they completed the HealthChange Methodology workshop through their organisation, which aims to educate providers in helping patients make the behaviour changes needed to promote health; such training impacts provider-patient interactions and could impact SDM as patient-centred communication is discussed. ${ }^{48}$ Survey completion took $5-7 \mathrm{~min}$ per timepoint.

In a pilot feasibility study, we completed the following data collection strategies at two community rehabilitation sites with the modification that T1 would be at 6 weeks after recruitment (vs 3 months). The data collected were used to determine study logistics feasibility and the reliability of the ASK-MI results (via Cronbach's alpha determination).

A novel, dyadic SDM tool was used given the infeasibility of using a third-party reviewer, and the challenges in using the SDM-Q-9 in similar Alberta populations: the ASK-MI (figure 1 shows the patient version; provider version is same except language transposed to address provider). Using a 6-point Likert Scale (with not-applicable option), patients and providers independently describe the appointment experience from a SDM-process perspective. This process involves patients and providers agreeing on the main concern; working together to make a plan that considers patients' wishes; and ensuring the provider confirms patient understanding and next steps. The
ASK-MI was developed and piloted in primary care and mental health clinics in Alberta. ${ }^{43}$

The dyadic ASK-MI tool requires patient and provider to independently rate six facets of the SDM experience; lower numeric scores reflect higher quality SDM. Individual scores are summed; the two sum scores are compared with determine the final rating score: excellent, acceptable or unacceptable. When both patient and provider rate SDM highly, an excellent rating score is reached. Disparity between parties would lead to a lower ASK-MI rating score. Full agreement on SDM excellence equates to patient and provider both giving the best, lowest numeric score on each ASK-MI item. Using selfreport, we collected contextual (eg, group or individual appointment; were goals set with provider) and participant demographic data (eg, age, gender, marital status).

The WatLX is a two-page outpatient rehabilitation care patient experience survey meant for post completion of rehabilitation care. The WatLX consists of 10 questions, where respondents can respond either not applicable or on a 7-point Likert scale. Psychometric testing of the WatLX involved 1174 cognitively intact, English-speaking, adult outpatients who had completed a programme of cardiac, musculoskeletal, neurologic, stroke, pulmonary or speech language rehabilitative care in Ontario. ${ }^{49}$ Reliability analyses compared the use of a 7-point to 5-point Likert scale in the WatLX. Cronbach's alphas were 0.863 and 0.957 for the 5-point and 7-point scale, and the ICC $=0.827$ and 0.880 , respectively. ${ }^{49}$ Generally, the higher the score, the more positive the patient experience. There is evidence of ceiling effects with the WatLX.

The T0 take-home study package included a consent form and directions, the ASK-MI survey, a patient demographic form including their communication preference for the 3-month follow-up (T1) surveys (which included WatLX). All envelopes were preaddressed and stamped to support convenient, confidential return to the researchers. Patients were directed to complete the surveys within 24 hours, so their appointment was fresh in their mind.

When a patient took a study package, the recruiter logged the date, envelope number, patient's initials and provider name. Daily, this recruitment information was sent to the lead researcher, who emailed the ASK-MI (provider version) tool to the named provider, along with the patient initials via personalised email link to REDCap at the University of Alberta. Providers received one email per patient and had 48 hours to complete the survey.

The second timepoint (T1), for patients only, was exactly 3 months post recruitment. T1 data collection was by mail or email per patient-participant preference. Participants received email or phone reminders 1 week prior to T1, and at 7 days post $\mathrm{T} 1$.

To ensure the accuracy of data entry of paper surveys, a randomly selected $30 \%$ of the study sample was assessed at the close of data collection. If more than $10 \%$ of the data were incorrectly entered, then another random $30 \%$ 


\begin{tabular}{|c|c|c|c|c|c|c|c|}
\hline Alberta & aared & ecisi & $\begin{array}{l}\text { Makil } \\
\text { (Patient/C }\end{array}$ & $\begin{array}{l}\text { g } \mathbf{M e} \\
\text { ent) }\end{array}$ & urem & at Ins & ament \\
\hline $\begin{array}{l}\text { The purpose of this } \\
\text { provider. A shared } \\
\text { based on the best av } \\
\text { anyone with whom y } \\
\text { practitioner, a dietici }\end{array}$ & $\begin{array}{l}\text { is to gath } \\
\text { sion is on } \\
\text { ole eviden } \\
\text { have a cli } \\
\text { a social w }\end{array}$ & $\begin{array}{l}\text { formati } \\
\text { t you ar } \\
\text { ind your } \\
\text { l appoin } \\
\text { er, a me }\end{array}$ & $\begin{array}{l}\text { about share } \\
\text { your health } \\
\text { eferences. F } \\
\text { ent regardin } \\
1 \text { health ther }\end{array}$ & $\begin{array}{l}\text { decision } \\
\text { are provic } \\
\text { r the purp } \\
\text { your hea } \\
\text { pist, or ar }\end{array}$ & $\begin{array}{l}\text { aking bety } \\
\text { r make to } \\
\text { ses of this } \\
\text { a, such as } \\
\text { exercise sp }\end{array}$ & $\begin{array}{l}\text { n you anc } \\
\text { her, after } \\
\text { ol, a healt } \\
\text { hysician, } \\
\text { ialist. }\end{array}$ & $\begin{array}{l}\text { our health } \\
\text { nsidering o } \\
\text { care provid } \\
\text { nurse, a nu }\end{array}$ \\
\hline Instructions: Put an & each row & indicate & w strongly y & $\mathrm{u}$ agree $\mathrm{o}$ & disagree. & & \\
\hline & $\begin{array}{l}\text { Strongly } \\
\text { Agree }\end{array}$ & $\begin{array}{l}\text { Mostly } \\
\text { Agree }\end{array}$ & $\begin{array}{l}\text { Moderately } \\
\text { Aoree }\end{array}$ & Slightly & Mostly & Strongly & Not \\
\hline $\begin{array}{l}\text { Q1. My health care } \\
\text { provider and I agreed } \\
\text { on the main concern(s) } \\
\text { and focus of the visit. }\end{array}$ & & & & & & & \\
\hline $\begin{array}{l}\text { Q2. My health care } \\
\text { provider and I worked } \\
\text { together to make a } \\
\text { plan that addressed my } \\
\text { preferences. }\end{array}$ & & & & & & & \\
\hline $\begin{array}{l}\text { Q3. The plan that my } \\
\text { health care provider } \\
\text { and I made considered } \\
\text { my wishes and } \\
\text { abilities. }\end{array}$ & & & & & & & \\
\hline $\begin{array}{l}\text { Q4. My health care } \\
\text { provider checked } \\
\text { that I understood the } \\
\text { plan. }\end{array}$ & & & & & & & \\
\hline $\begin{array}{l}\text { Q5. My health care } \\
\text { provider checked if I } \\
\text { could follow the plan } \\
\text { between now and my } \\
\text { next appointment. }\end{array}$ & & & & & & & \\
\hline $\begin{array}{l}\text { Q6. I agreed with the } \\
\text { plan my health care } \\
\text { provider and I made. }\end{array}$ & & & & & & & \\
\hline Comments: & & & & & & & \\
\hline
\end{tabular}

Figure 1 The Alberta Shared decision-maKing Measurement Instrument.

of the study sample would have been checked. Errors were rectified immediately.

At the close of data collection, the research team developed a coding rubric by consensus to capture the presence, and level, of function in the rehabilitation goals perceived by patient participants (as described in the self-reported patient sociodemographic form). Level of functionality was informed by the Alberta Health Services definition that the goal "consider[ed] the whole person-individual context, personal factors, and how a health condition impacts participation in life... work, school, play, relationships, roles and any activities that the person loves to do ${ }^{50}$ A goal was functional, if it related to participation in a role, responsibility or activity important to the person; the language of the goal spoke to activity and participation in life not the rehabilitation treatment plan. A goal was not functional if it did not speak to such a role, responsibility or activity important to the person (eg, language focused on the treatment plan or general alleviation of symptoms). While one researcher (KPM) coded all patient-participant self-reported perceptions, the team discussed and practised the coding together to ensure consensus on approaches to described goals.

\section{Data analysis}

After cleaning and coding the T0 and T1 data, we completed descriptive and exploratory analyses to address the research questions. The ASK-MI Score was collapsed into two different binary categorical variables: (1) excellent versus acceptable/unacceptable; and (2) full agreement on SDM excellence versus not full agreement on SDM Score. The secondary variable was overall rehabilitative care experience (WatLX). Independent variables included age, gender, patient income range, geographical area and other demographic and contextual variables.

The distribution of interval and ratio type survey data (eg, age) was checked for whether it is normally distributed. Test selection was based on the results of these 
analysis (eg, non-normally-distributed data were analysed using non-parametric tests). We analysed the questionnaire data descriptively, with means, SD, both overall in community rehabilitation and based on contextual differences. For categorical data, $\chi^{2}$ tests directed comparisons between high-quality versus low-quality SDM; subanalyses using tests of proportions considered this ratio of experiences in different demographic and organisational settings based on the size and quality of independent variable data collected. For the three surveys, where missing data were less than $5 \%$ across population, then used the $20 \%$ as the threshold for missing items: if $\leq 20 \%$ items missing, then median response used in place of the missing item to then score the survey; if $>20 \%$ of items missing, then the entire record was deleted from the analysis. ${ }^{51}$ Univariate correlations were studied between each independent variables (age, gender, income, geographical area, provider discipline) and the ASK-MI score. A binary regression was completed to ascertain the effects of training (ie, HealthChange participation), level of privacy during appointment, geographical setting and timing of appointment (relative to patient's rehabilitation care journey). This model used a binomial distribution with log link function to obtain relative risks. We used backward elimination with the Akaike Information Criterion (AIC) to reduce the model. At each step, the variables with the largest associated decrease in the AIC at removal was deleted from the model. The steps continued until the removal of remaining variable resulted in an increase in the AIC.

\section{RESULTS}

\section{Pilot feasibility study results}

Phase 1 involved two community rehabilitation sites in an urban-metropolitan area in Alberta between March and May 2018 ( $\mathrm{n}=24$ patients and $\mathrm{n}=6$ providers). The mean (range) participant age for patients and providers was 48.3 (22-71) and 37.4 (26-56) years, respectively. Most participants were white $(87.5 \%$ patients; $80 \%$ providers $)$ and women $(66.7 \%$ patients; $60 \%$ providers). Fifty per cent of patient-participants were employed, while $20.8 \%$ were retired. Patient-participants' total family income varied with $37.5 \%$ being affluent $(\geq \$ \mathrm{C} 150000)$ and a combined $20.8 \%$ being less affluent $(<\$ C 35000)$. On average (range), provider participants had 12 (3-30) years of experience and worked 31.7 (10-70) hours weekly.
Because only four patients completed follow-up surveys that included the WatLX, we only assessed the reliability of the EuroQol (EQ-5D-5L) and ASK-MI surveys in this population. Table 1 describes the tools' means, SD and internal consistency assessments using Cronbach's alpha. Given the small sample, the reliability of these measures appear appropriate and related to estimates during tool development. ${ }^{52}$ Field notes support the validity of the EQ-5D-5L and ASK-MI tools for participants. The ASK-MI scores were clustered in the excellent range, which is common to many patient-reported experience measures. The ASK-MI was completed by 24 patient-provider dyads. The scores obtained from these dyads scoring the SDM experience as excellent $(70.8 \%)$, acceptable $(29.2 \%)$, or unacceptable $(0 \%)$. Because complementary studies by study coauthors detail the psychometric validity of the instrument, we do not present further findings in that regard (for details, contact coauthors as the manuscript is under review).

\section{Participant information (full study)}

Thirteen community-rehabilitation sites distributed 606 take-home survey packages; 341 patients returned them and thus implied consent to participate (response rate 56.2\%). At T1, 209 patients returned surveys (response rate $61.3 \%$, the remainder lost to follow-up).

Table 2 describes the patient-participant population. The patient-participants' mean (SD) age was 57.5 (16.4) years. Most patient-participants were women $(58.9 \%)$, married (68.9\%), Caucasian (90.9\%), had some postsecondary education $(70.4 \%)$, were at a 1:1 appointment with providers $(90.9 \%)$, were neither at the first nor last appointment at recruitment $(66.9 \%)$ and were receiving physiotherapy $(68.6 \%)$. Participants varied in where they received their care: $46.3 \%$ were in an open exercise area, $48.4 \%$ were in a private area (either behind a privacy curtain or in private room) and $3.8 \%$ described their area as unique. The demographic profile was similar between $\mathrm{T} 0$ and $\mathrm{T} 1$ patient-participants.

Table 3 describes the provider-participant population. The provider-participants' mean (SD) age was 41.8 (9.86) years. Experience wise, providers had a mean (SD) of 15.1 (10.3) years of experience. Providers represented six rehabilitation disciplines, with physiotherapy $(53.0 \%)$ and occupational therapy (19.7\%) being most prevalent. Most providers were women (60.6\%), Caucasian (60.6\%),

Table 1 Internal consistency of surveys in pilot feasibility study

\begin{tabular}{|c|c|c|c|c|}
\hline Tool & Mean & SD & $\begin{array}{l}\text { Internal consistency } \\
\text { measurement tool }\end{array}$ & $\begin{array}{l}\text { Internal consistency } \\
\text { measurement }\end{array}$ \\
\hline ASK-MI & $\begin{array}{l}6.96 \text { (patients) } \\
10 \text { (providers) }\end{array}$ & $\begin{array}{l}1.93 \text { (patients) } \\
4.07 \text { (providers) }\end{array}$ & Cronbach's alpha & 0.82 \\
\hline EQ-5D-5L & $\begin{array}{l}73.6 \% \text { (VAS) } \\
0.760 \text { (EQ-5D Index score) }\end{array}$ & $\begin{array}{l}13.7 \text { (VAS) } \\
0.104 \text { (EQ-5D Index score) }\end{array}$ & Cronbach's alpha & 0.648 \\
\hline
\end{tabular}

ASK-MI, Alberta Shared decision-maKing Measurement Instrument; VAS, Visual Analogue Scale. 
Table 2 Patient-participant demographics

\begin{tabular}{lc}
\hline & N (\%) \\
\hline Patient population & $341(100 \%)$ \\
\hline Mean age in years (SD) & $57.5(16.4)$ \\
\hline Missing & $3(0.9 \%)$ \\
\hline Gender & \\
\hline Male & $138(40.5 \%)$ \\
\hline Female & $201(58.9 \%)$ \\
\hline Missing & $2(0.6 \%)$ \\
\hline Marital status & \\
\hline Single & $48(14.1 \%)$ \\
\hline Married (legal/common law) & $235(68.9 \%)$ \\
\hline Separated or divorced & $32(9.4 \%)$ \\
\hline Widowed & $21(6.2 \%)$ \\
\hline Missing & $5(1.5 \%)$ \\
\hline Geographical location & $145(42.5 \%)$ \\
\hline Metropolitan-urban & $161(47.2 \%)$ \\
\hline Regional-urban & $35(10.3 \%)$ \\
\hline Rural &
\end{tabular}

Education

\begin{tabular}{|lc|}
\hline High school diploma or less & $96(28.1 \%)$ \\
\hline Any postsecondary education & $240(70.4 \%)$ \\
\hline Missing & $5(1.5 \%)$ \\
\hline Employment status & \\
\hline Employed & $141(41.3 \%)$ \\
\hline Unemployed & $61(17.9 \%)$ \\
\hline Retired & $135(39.6 \%)$ \\
\hline Missing & $4(1.2 \%)$ \\
\hline Ethnicity & \\
\hline European origins & $310(90.9 \%)$ \\
\hline Indigenous (eg, Inuk, Métis) & $10(2.9 \%)$ \\
\hline Non-European origins & $21(6.2 \%)$ \\
\hline Supplementary insurance & \\
\hline Yes & $144(42.2 \%)$ \\
\hline No & $160(46.9 \%)$ \\
\hline Prefer not to answer & $37(10.9 \%)$ \\
\hline Total family income & $106(31.1 \%)$ \\
\hline Less than \$C59 999 & $75(22.0 \%)$ \\
\hline \$C60 000-99999 & $78(22.9 \%)$ \\
\hline \$C100 000 or more & $82(24 \%)$ \\
\hline Prefer not to answer & \\
\hline
\end{tabular}

trained in Canada $(66.7 \%)$ and had primarily clinical provider roles (vs management; $71.2 \%$ ).

Table 4 describes the provider-participants' work settings. Providers worked a mean (SD) of 31.8 (9.0) hours/week in direct patient care, and saw a mean (SD) of 28.8 (17.6) patients per week. The outpatient clinical
Table 3 Provider-participant demographics

\begin{tabular}{ll}
\hline Provider participant characteristics & N (\%) or mean (SD) \\
\hline Population & 66 \\
\hline Age (years) & $41.83(9.86)$ \\
\hline Missing & $13(19.7 \%)$ \\
\hline Gender & \\
\hline Male & $13(19.7 \%)$ \\
\hline Female & $40(60.6 \%)$ \\
\hline Missing & $13(19.7 \%)$ \\
\hline Provider discipline & \\
\hline Occupational therapy & $13(19.7 \%)$ \\
\hline Physiotherapy & $35(53.0 \%)$ \\
\hline Other & $5(7.5 \%)$ \\
\hline Missing & $13(19.7 \%)$ \\
\hline Country of training & \\
\hline Canada & $44(66.7 \%)$ \\
\hline Outside of Canada & $9(13.6 \%)$ \\
\hline Missing & $13(19.7 \%)$ \\
\hline Ethnicity & \\
\hline European Ethnic Origins & $40(60.6 \%)$ \\
\hline Non-European Ethnic Origins & $8(12.1 \%)$ \\
\hline Missing & $18(27.2 \%)$ \\
\hline Geographical location & \\
\hline Metropolitan-urban & $36(54.5 \%)$ \\
\hline Regional-urban & $24(36.4 \%)$ \\
\hline Rural & $6(9.1 \%)$ \\
\hline
\end{tabular}

settings varied for providers, including community-based $(31.8 \%)$ and hospital-based $(45.5 \%)$ clinics. The clinical populations included at least 10 diverse populations, including general adults $(25.8 \%)$, musculoskeletal $(16.7 \%)$ and neurorehabilitation (13.6\%). Providers were evenly split on participation in a person-centred behaviour-change course (HealthChange Method$\operatorname{ology}^{53}$ ): $39.4 \%$ said they had taken it, $40.9 \%$ said they had not taken it and $19.7 \%$ responses were missing herein. Of the providers who had taken HealthChange, most providers perceived that it influenced their patient interactions to some degree $(76.9 \%)$ (vs to a great degree $(15.4 \%))$. The perceived influence of HealthChange on site processes was less clear: $42.3 \%$ of providers saw no influence, while $53.8 \%$ saw some degree of influence.

\section{SDM and goal-setting prevalence in community rehabilitation}

Using current ASK-MI scoring guidelines, $78.9 \%$ of T0 patient-provider appointments rated excellent (table 5). Given the evident floor effect of the ASK-MI (ie, more than $15 \%$ of respondents have the lowest score, which is the best value $\left.{ }^{54}\right)$, the survey developers will reassess the scoring algorithm. ${ }^{43}$

Looking at full agreement on SDM excellence or not, at T0, $26.4 \%$ of patient-provider encounters involved full 
Table 4 Provider-participants' clinical setting

N (\%) or mean

Provider participant characteristics

(SD)

\begin{tabular}{|c|c|}
\hline \multicolumn{2}{|l|}{ Setting } \\
\hline Community-based clinic & $21(31.8 \%)$ \\
\hline Hospital, outpatient clinic & $30(45.5 \%)$ \\
\hline \multicolumn{2}{|l|}{ Primary patient population } \\
\hline Complex adults & $2(3.0 \%)$ \\
\hline Hand/foot/cardiac & $4(6.0 \%)$ \\
\hline General adults & $17(25.8 \%)$ \\
\hline Musculoskeletal (MSK) & $11(16.7 \%)$ \\
\hline Neuro & $9(13.6 \%)$ \\
\hline Ortho/surgery & $3(4.5 \%)$ \\
\hline Seniors & $4(6.1 \%)$ \\
\hline Missing & $16(24.2 \%)$ \\
\hline Average waitlist (days) for clinic & $16.59(17.59)$ \\
\hline Missing & $18(27.3 \%)$ \\
\hline \multicolumn{2}{|l|}{ HealthChange completion } \\
\hline Yes & $26(39.4 \%)$ \\
\hline No & $27(40.9 \%)$ \\
\hline Missing & $13(19.7 \%)$ \\
\hline \multicolumn{2}{|c|}{ HealthChange influenced patient interactions? } \\
\hline \multicolumn{2}{|l|}{ No influence } \\
\hline To some degree & $1(3.8 \%)$ \\
\hline To a great degree & $20(76.9 \%)$ \\
\hline Missing & $4(15.4 \%)$ \\
\hline HealthChange influenced site processes? & $1(3.8 \%)$ \\
\hline No influence & $11(42.3 \%)$ \\
\hline To some degree & $14(53.8 \%)$ \\
\hline To a great degree & $0(0 \%)$ \\
\hline Missing & $1(3.8 \%)$ \\
\hline
\end{tabular}

agreement on SDM excellence. Figures 2 and 3 display the frequency of responses across the 6-item Likert scale for each ASK-MI question for patients and providers, respectively. These two graphs reveal that, across the six items, providers agreed less often about SDM excellence (ie, relatively fewer responses at 'strongly agree').

For patients, there was less agreement that the patient and provider planned together to address the patient's preferences and that the plan considered the patient's wishes and abilities. Patients more often strongly agreed that the provider checked the patient's understanding of the plan and that there was agreement on the plan created.

For providers, there was less agreement that the patient and provider worked together to make a plan that addressed patient preferences. Providers more often strongly agreed that there was clarity and agreement on the visit's main focus; that the provider checked for
Table 5 Prevalence of shared decision-making and goal setting

\begin{tabular}{lc}
\hline Shared decision-making experience & $\begin{array}{l}\text { N (\%) or mean } \\
\text { (SD) }\end{array}$ \\
\hline ASK-MI Score & \\
Excellent & $269(78.9 \%)$ \\
Acceptable & $37(10.9 \%)$ \\
Unacceptable & $2(0.6 \%)$ \\
Missing/unable to calculate & $14(4.1 \%)$
\end{tabular}

Patient and provider had full agreement on

SDM excellence

$\begin{array}{lc}\text { Full agreement } & 90(26.4 \%) \\ \text { Less than full agreement } & 218(63.9 \%) \\ \text { Missing/unable to determine } & 14(4.1 \%) \\ \text { Was a goal set with provider? } & \\ \text { Yes } & 270(79.2 \%) \\ \text { No } & 67(19.6 \%) \\ \text { Missing } & 4(1.2 \%)\end{array}$

Level of functionality of the patient-stated goal

$\begin{array}{lc}\begin{array}{l}\text { Highly functional, focused on everyday } \\ \text { activity (ie, patient language) }\end{array} & 39(11.4 \%) \\ \begin{array}{l}\text { Moderately functional, focused on } \\ \text { general mobility }\end{array} & 140(41.1 \%) \\ \begin{array}{l}\text { Not functional, focused on treatment } \\ \text { plan (ie, provider language) }\end{array} & 76(22.3 \%) \\ \begin{array}{l}\text { Not applicable, no goal was set or goal } \\ \text { not provided }\end{array} & 86(25.2 \%)\end{array}$

patient understanding; and that the patient and provider agreed on the plan created.

Table 6 compares the three geographical settings on prevalence of high-quality SDM (ie, full agreement on SDM excellence) in patient-provider encounters, which demonstrates no statistically significant differences in the quality of SDM experiences between geographical areas: metropolitan areas (19.9\%) and regional areas $(33.8 \%$; $\mathrm{p}=0.068$ ).

At T0, 19.4\% of patients stated that they had not set a goal for their rehabilitation care (figure 4). When patients had set a goal, they were asked to describe the goal. We categorised the patient-perceived goals based on level of functionality (table 5). Only $11.4 \%$ of patients stated goals that met the Alberta Health Services' definition of functionality. A broader definition of functionality includes goals that aim for general improvements in, for example, mobility or strength. Under this broad definition, $42.6 \%$ of patients perceive their rehabilitation goals as aimed towards achievements or activities important to their life (figure 5). Some $22.3 \%$ of patients perceived goals as equal to the treatment plan (eg, doing home exercises, coming to appointments). 


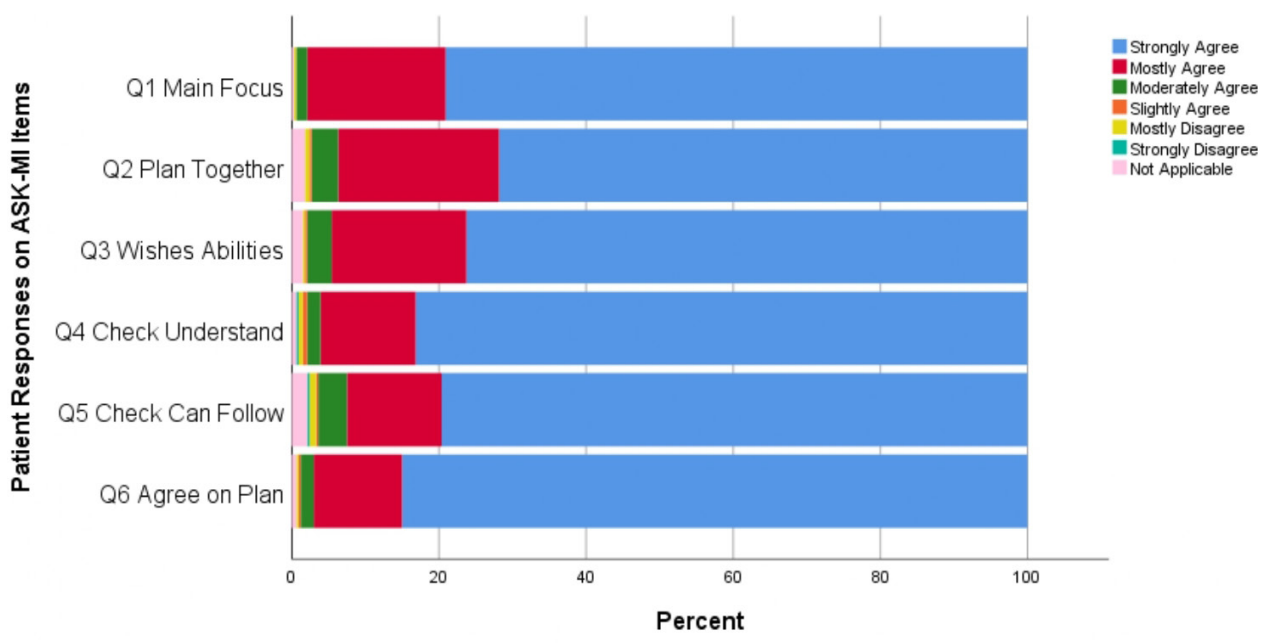

Figure 2 Patient responses on the six Alberta Shared decision-maKing Measurement Instrument (ASK-MI) items on shared decision-making experience.

\section{SDM, goal setting and associated factors}

In the first phase, we used univariate $\chi^{2}$ tests of correlation. SDM experience quality was not associated with whether patients' perceived that goals were set or whether patients' perceived goals that were functional. SDM experience was not associated with other immutable patient characteristics (eg, gender, education, employment status, insurance access, income) or appointment type (table 7). The only patient-related features associated with SDM timing of appointment $(65.1 \%$ high-quality SDM vs $58.0 \%$ less-quality SDM, $\mathrm{p}=0.035$ ).

SDM experience was not associated with the providers' experience (in years since graduation) or the time since the provider took HealthChange. SDM was not statistically significantly associated with other features such as more privacy during the appointment $(60.2 \%$ highquality SDM vs 50.7\% in low-quality SDM, $\mathrm{p}=0.070$ ), nonphysiotherapy (74.4\% physiotherapy in high-quality SDM vs $81.3 \%$ physiotherapy in low-quality SDM, $\mathrm{p}=0.091$ ) and if the provider had taken HealthChange $(73.9 \%$ in highquality SDM vs only $41.2 \%$ high-quality SDM if not taken, $\mathrm{p}=0.085$ ).

SDM and goal setting varied across the three geographical areas (table 5). More providers had taken HealthChange $(p<0.001)$ in regional settings compared with rural and metropolitan settings. There was no difference in the proportion of patients with functional goals across geographies. Demographically, more patients had lower total family income in regional areas $(40.9 \%$ lowest income bracket vs $26.1 \%$ (metropolitan) or $20.6 \%$ (rural), $\mathrm{p}<0.001$ ). Contextually, metropolitan-urban areas were unique in that fewer appointments were in private areas $(31.7 \%$ vs $69.2 \%$ in regional and $68.6 \%$ in rural, $\mathrm{p}<0.001$ ) and fewer providers had taken person-centred behaviour-change training (HealthChange) (20.7\% vs $56.7 \%$ in regional and $40.0 \%$ in rural, $\mathrm{p}<0.001)$. Finally, occupational therapy was represented least often in regional-urban appointments $(10.6 \%$ vs $27.0 \%$ (metropolitan) and $25.7 \%$ (rural), $\mathrm{p}=0.007$ ).

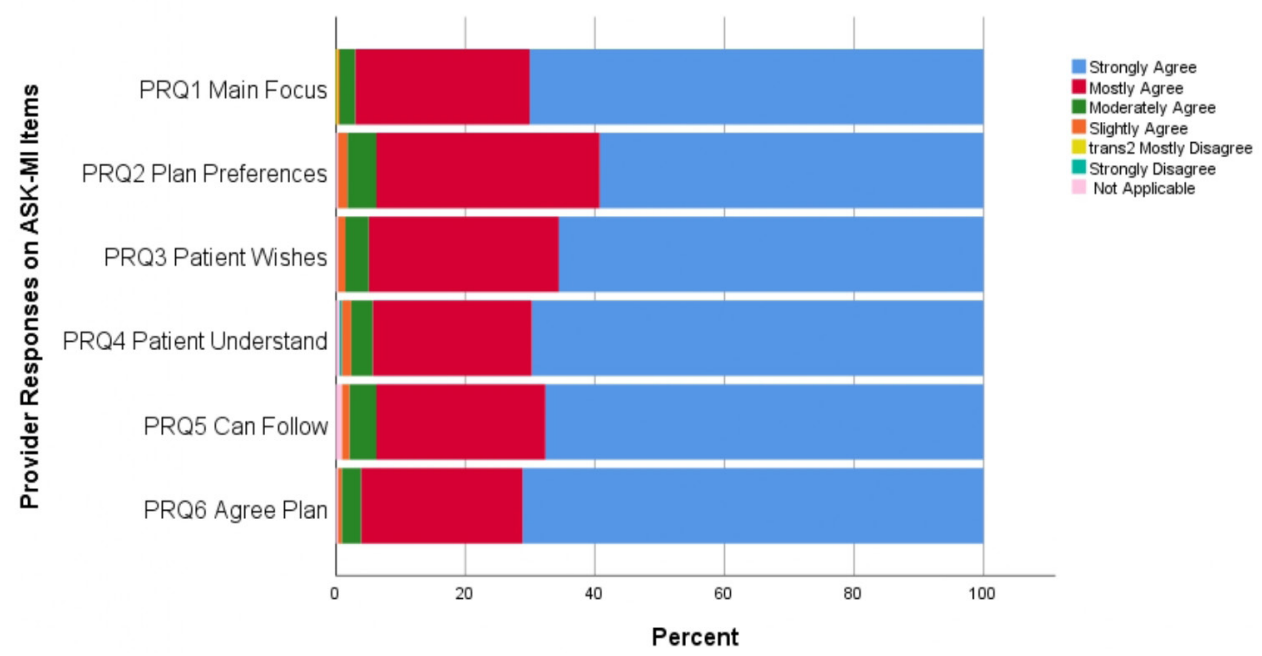

Figure 3 Provider responses on the six Alberta Shared decision-maKing Measurement Instrument (ASK-MI) items on shared decision-making experience. 
Table 6 Comparison of three geographical areas on shared decision-making (SDM), demographic and contextual variables

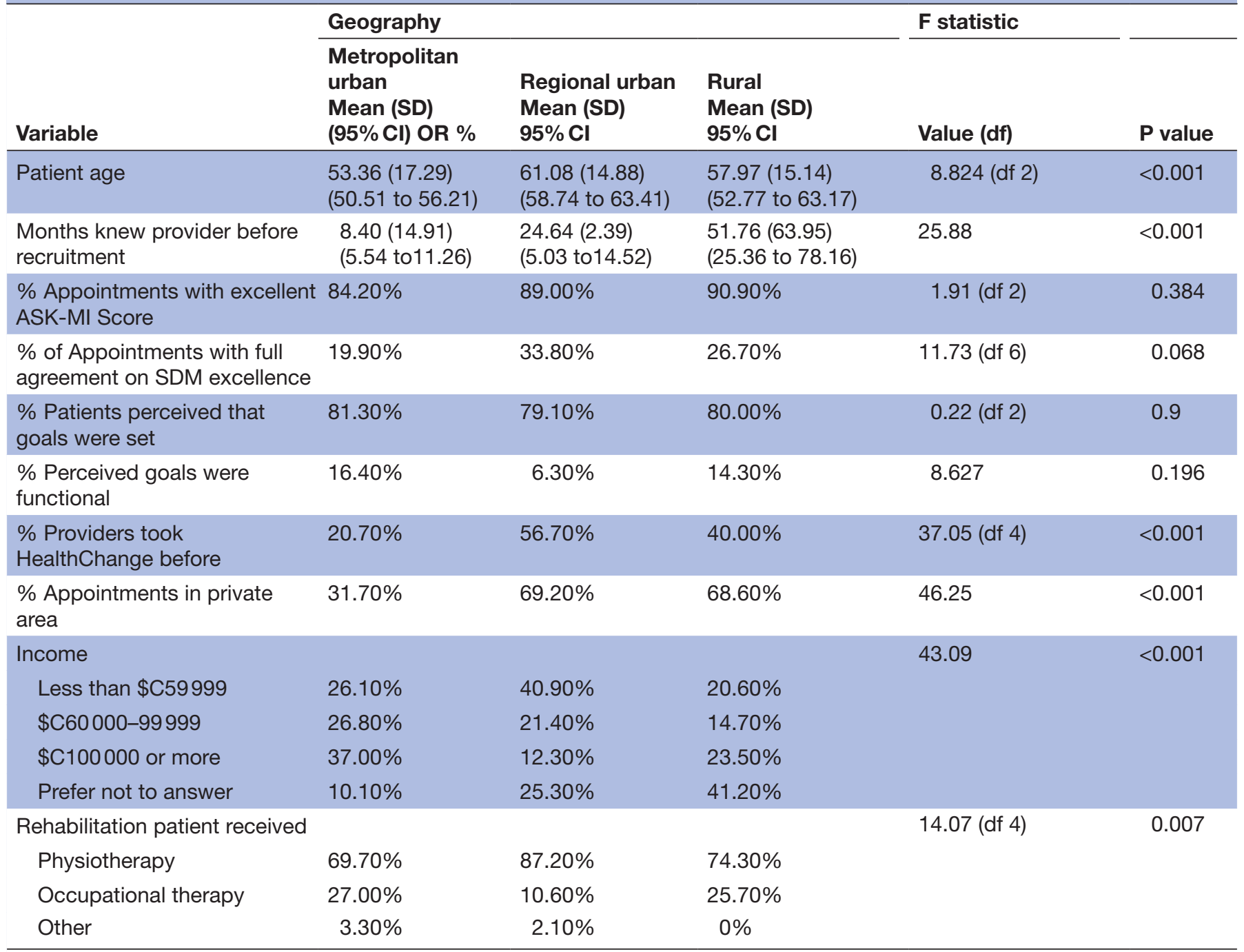

ASK-MI, Alberta Shared decision-maKing Measurement Instrument.

A backwards, stepwise logistic regression was performed to ascertain the effects of appointment timing at recruitment, level of privacy (per location at setting), geographical setting and whether the provider took HealthChange on the likelihood that the patient and provider fully agreed on the excellence of the SDM experience. The final model included HealthChange training and geographical setting, while appointment timing and

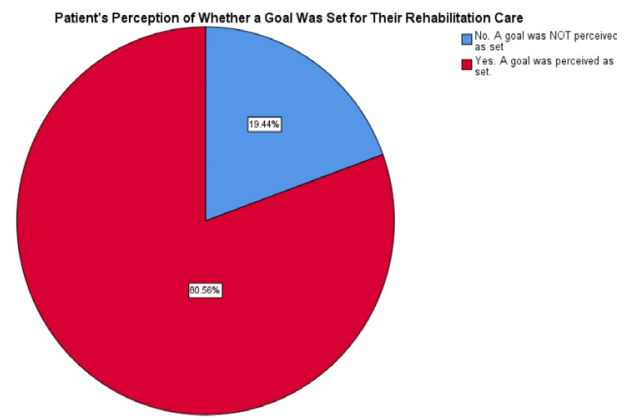

Figure 4 Patient perceptions of goal setting occurrence. privacy were removed as not statistically significant. The final model reveals the following relative risks (95\% CI, p value): 2.463 (1.650 to $3.816, \mathrm{p}<0.001)$ for regional versus metropolitan settings; 1.399 ( 0.646 to $2.652, \mathrm{p}=0.329)$ for rural versus metropolitan settings; and 0.439 (0.284 to $0.649, \mathrm{p}<0.001$ ) for taken HealthChange versus not taken. Providers who took the training were less likely to rate their interactions with the highest score $(37 / 119=31.6 \%)$

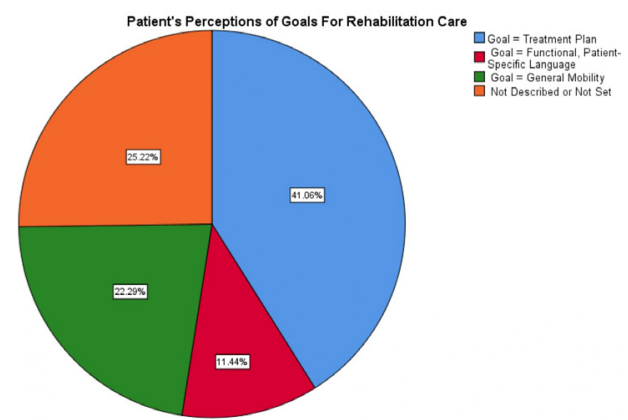

Figure 5 Level of functionality of patient-stated goals. 
Table 7 Relationship between full agreement on shared decision-making (SDM) (high-quality SDM) and other demographic or contextual factors

\begin{tabular}{|c|c|c|c|c|}
\hline \multirow[b]{2}{*}{ Variable } & \multicolumn{2}{|c|}{$\begin{array}{l}\text { Patient and provider full agreement on } \\
\text { SDM excellence? }\end{array}$} & \multirow[b]{2}{*}{ Pearson $\chi^{2}$ value $(\mathrm{df})$} & \multirow[b]{2}{*}{$P$ value } \\
\hline & $\begin{array}{l}\text { Yes } \\
\text { Count (\%) }\end{array}$ & $\begin{array}{l}\text { No } \\
\text { Count (\%) }\end{array}$ & & \\
\hline \multicolumn{5}{|l|}{ Seen provider before recruitment? } \\
\hline Yes & 76.90 & 74.40 & 0.313 (df 2) & 0.855 \\
\hline No & 23.10 & 25.60 & & \\
\hline \multicolumn{5}{|c|}{ Appointment timing at recruitment } \\
\hline First appointment & 27.90 & 22.60 & 13.57 (df 6) & 0.035 \\
\hline Near start of care & 37.20 & 35.40 & & \\
\hline Near end of care & 30.20 & 38.70 & & \\
\hline Last appointment & 4.70 & 3.30 & & \\
\hline \multicolumn{5}{|l|}{ Appointment type } \\
\hline Group & 6.60 & 9.50 & 0.734 (df 2) & 0.693 \\
\hline Individual & 93.40 & 90.50 & & \\
\hline \multicolumn{5}{|l|}{ Where in facility } \\
\hline Open area & 39.80 & 49.30 & 7.05 (df 3) & 0.07 \\
\hline Private area or other & 60.20 & 50.70 & & \\
\hline \multicolumn{5}{|l|}{ Patient perceived goals set? } \\
\hline Yes & 80.20 & 81.70 & 2.567 (df 2) & 0.277 \\
\hline No & 19.80 & 18.30 & & \\
\hline \multicolumn{5}{|c|}{ Perceived goals were functional? } \\
\hline Yes & 14.30 & 10.90 & & \\
\hline No & 85.70 & 89.10 & 0.793 (df 2) & 0.673 \\
\hline Female gender & 58.20 & 58.60 & 0.015 (df 2) & 0.993 \\
\hline \multicolumn{5}{|l|}{ Marital status } \\
\hline Married (incl common law) & 72.50 & 69.90 & 3.08 (df 3) & 0.379 \\
\hline Not, or no longer, married & 27.50 & 30.10 & & \\
\hline \multicolumn{5}{|l|}{ Education } \\
\hline High school diploma or less & 30.80 & 26.50 & 2.68 (df 3) & 0.443 \\
\hline Any postsecondary education & 69.20 & 73.50 & & \\
\hline \multicolumn{5}{|c|}{ Employment } \\
\hline Employed & 41.80 & 42.90 & $3.50(\mathrm{df} 6)$ & 0.743 \\
\hline Unemployed & 16.50 & 17.80 & & \\
\hline Retired & 41.80 & 39.30 & & \\
\hline \multicolumn{5}{|l|}{ Insurance } \\
\hline Yes & 45.10 & 43.80 & 7.515 (df 6) & 0.276 \\
\hline No & 41.80 & 48.40 & & \\
\hline Prefer not to answer & 13.20 & 7.80 & & \\
\hline \multicolumn{5}{|l|}{ Income } \\
\hline Less than $\$ C 59999$ & 34.30 & 50.00 & $5.91(\mathrm{df} 6)$ & 0.43 \\
\hline \$C60000-99999 & 27.40 & 23.50 & & \\
\hline$\$ C 100000$ or more & 13.90 & 11.80 & & \\
\hline Prefer not to answer & 24.30 & 14.70 & & \\
\hline Provider discipline & & & & \\
\hline
\end{tabular}


Patient and provider full agreement on SDM excellence?

\begin{tabular}{|c|c|c|c|c|}
\hline Variable & $\begin{array}{l}\text { Yes } \\
\text { Count (\%) }\end{array}$ & $\begin{array}{l}\text { No } \\
\text { Count (\%) }\end{array}$ & Pearson $\chi^{2}$ value (df) & $P$ value \\
\hline Physiotherapy & 74.40 & 81.30 & 12.69 (df 6) & 0.048 \\
\hline Other & 0 & 3.10 & & \\
\hline \multicolumn{5}{|l|}{ Provider took HealthChange? } \\
\hline No & 26.10 & 58.80 & & \\
\hline Provider trained in Canada & 85.30 & 83.20 & 0.264 (df 2) & 0.877 \\
\hline
\end{tabular}

when compared with providers who did not take the training $(82 / 178=47.4 \% ; \mathrm{p}<0.01)$. Provider training was not associated with patient ratings. Patients with providers who took the training did not rate their interactions as less favourable than patients with providers who did not take the training $(69 / 119=61.6 \%$ vs $110 / 178=64.7 \%$; $\mathrm{p}=0.876$ ).

Patients who perceived that a goal was set for their care saw a higher proportion of occupational therapists $(35.5 \%$ vs $14.7 \%, \mathrm{p}=0.001)$. While the time a provider knew the patient before T0 was associated with whether a goal was set $(p=0.054)$, the variance was high. Few other patient or provider characteristics were associated with patient perceptions of goal setting. Patient perceptions of goal setting for their rehabilitation did not differ by geographical setting, patient gender, marital status, education, employment status or total family income (table 8). Provider experience was not associated with patients' perceptions of goal setting. Provider HealthChange participation was not associated with patients' perception of goals setting or the functionality of the goal set.

Finally, the mean (SD) overall WatLX rating of patient experience was $8.97(1.39)$, where 10 was the highest rating. Item mean (SD) ratings ranged from 5.65 (1.35) to $6.79(0.579 ; 7$ was highest rating). Figure 6 demonstrates the distribution of responses along the 7-point Likert scale for these 10 items. The item with the greatest use of not applicable was having chosen family or friend given information that they needed about the patient's care, which suggests this question may not be relevant for many patients. The lowest rated items were for achieving treatment goals and controlling physical pain as much as possible. The highest rated items were for being treated with courtesy, feeling safe during treatment activities and would recommend to others.

The mean (SD) overall rehabilitation experience when patients' experienced high-quality SDM experiences was 9.07 (1.57), and was not different from the experience of participants who reported 'not high-quality' SDM (8.94 (1.41), $\mathrm{p}=0.735)$. Similarly, patient perceptions of a goal being set was not associated with patients' overall rehabilitation experience rating (9.03 (1.25) vs 8.72 (1.95), $\mathrm{p}=0.227)$.

\section{DISCUSSION}

These findings correspond with current literature but also provide a foundation for expansion. ${ }^{21} 23-25$ Previous literature reviews suggested very negative and limited SDM experiences in rehabilitation. ${ }^{21}$ A narrative synthesis $(n=15$ studies $)$ revealed that inpatient rehabilitation goal setting did not permit patient input, was overly controlled by staff, was challenging for time and patient-load reasons, and involved parties lacking SDM knowledge. ${ }^{21}$ Our data suggest that many patients and providers rate SDM quality high even though some providers do take a leading (or controlling) role. For patients, the lowest ratings relate to the recognition of patient preferences, which is at the heart of SDM. Providers were more critical than patients on SDM experiences, which suggests a receptivity to strategies to improve SDM. This critical nature may be expanded by training in patient-centred care principles. Our multivariate analysis revealed that exposure to HealthChange training decreased the likelihood of full agreement between the patient and provider on SDM excellence during the appointment. Further analyses revealed that provider training was not associated with patient ratings, but providers who took HealthChange training were less likely to rate their interactions with the best (lowest) score. This finding also suggests that perhaps patients who tended to judge interactions as positive also tended to have providers who had taken the course.

While the literature in rehabilitation often conflates goal setting and SDM, ${ }^{2155}$ our findings suggest that may be inappropriate. Patient-participant perceptions of whether goals were set, and the connection (or not) between set goals and patient lives calls for further investigation. Nearly 1 in 5 patients in this provincial health system did not set goals for their rehabilitation care. If goal functionality is modestly measured to include general and specific connections to patients' everyday activities, roles and responsibilities, then only every other patient set a goal in 
Table 8 Clinically relevant differences between whether patient set a goal or not during care and other variables

\section{Did patient perceive that a goal was} set for rehabilitation care?

\begin{tabular}{|c|c|c|c|c|}
\hline \multirow[b]{2}{*}{ Variable } & & \multirow[b]{2}{*}{$\begin{array}{l}\text { Test statistic value } \\
\text { (df) }\end{array}$} & \multirow[b]{2}{*}{$P$ value } \\
\hline & $\begin{array}{l}\text { Yes } \\
\text { Mean (SD) } \\
\text { OR \% }\end{array}$ & $\begin{array}{l}\text { No } \\
\text { Mean (SD) } \\
\text { OR \% }\end{array}$ & & \\
\hline WatLX overall rehabilitation experience & $9.034(1.251)$ & $8.717(1.953)$ & $\mathrm{F}=1.47(\mathrm{df} 1)$ & 0.227 \\
\hline Patient age at T0 & $57.23(15.92)$ & $57.30(18.14)$ & $F=0.001(d f 1)$ & 0.974 \\
\hline Provider's experience & $14.05(10.67)$ & $13.91(10.17)$ & $F=0.008(d f 1)$ & 0.93 \\
\hline Time patient knew provider & $11.51(24.63)$ & $21.93(51.61)$ & $F=3.760($ df 1$)$ & 0.054 \\
\hline Months since provider took HealthChange & $11.87(19.86)$ & $19.65(26.73)$ & $F=2.546($ df 1$)$ & 0.113 \\
\hline$\%$ Patients with female gender & $59.60 \%$ & $54.00 \%$ & $\chi^{2}=0.666(\mathrm{df} 1)$ & 0.414 \\
\hline$\%$ Providers took HealthChange & $39.20 \%$ & $42.60 \%$ & $\chi^{2}=0.474(\mathrm{df} 2)$ & 0.789 \\
\hline Where in facility & & & $\chi^{2}=2.780(\mathrm{df} 1)$ & 0.095 \\
\hline Open area & $49.10 \%$ & $37.50 \%$ & & \\
\hline Private area or other & $50.90 \%$ & $62.50 \%$ & & \\
\hline Marital status & & & $\chi^{2}=0.910(\mathrm{df} 1)$ & 0.34 \\
\hline Married (incl common law) & $190(71.2 \%)$ & $43(65.2 \%)$ & & \\
\hline Not, or no longer, married & $77(28.8 \%)$ & $23(34.8 \%)$ & & \\
\hline Education & & & $\chi^{2}=1.612(\mathrm{df} 1)$ & 0.204 \\
\hline High school diploma or less & $72(27.0 \%)$ & $23(34.8 \%)$ & & \\
\hline Any postsecondary education & $195(73.0 \%)$ & $43(65.2 \%)$ & & \\
\hline Employment & & & $\chi^{2}=2.316(\mathrm{df} 2)$ & 0.314 \\
\hline Employed & $118(44.2 \%)$ & $23(34.3 \%)$ & & \\
\hline Unemployed & $46(17.2 \%)$ & $15(22.4 \%)$ & & \\
\hline Retired & $103(38.6 \%)$ & $29(43.3 \%)$ & & \\
\hline Income & & & $\chi^{2}=2.458(\mathrm{df} 3)$ & 0.483 \\
\hline Less than \$C59999 & $80(30.7 \%)$ & $25(40.3 \%)$ & & \\
\hline \$C60000-99999 & $63(24.1 \%)$ & $11(17.7 \%)$ & & \\
\hline$\$ C 100000$ or more & $64(24.5 \%)$ & $14(22.6 \%)$ & & \\
\hline Prefer not to answer & $54(20.7 \%)$ & $12(19.4 \%)$ & & \\
\hline Provider discipline & & & $\chi^{2}=13.79(\mathrm{df} 2)$ & 0.001 \\
\hline Physiotherapy & $192(82.8 \%)$ & $39(62.9 \%)$ & & \\
\hline Occupational therapy & $34(14.7 \%)$ & $22(35.5 \%)$ & & \\
\hline Other & $6(2.6 \%)$ & $1(1.6 \%)$ & & \\
\hline
\end{tabular}

language that was meaningful to their lives and activities. Patient engagement and SDM are strategies to support movement towards meaningful goal setting, which itself supports patients in working on treatment plans that motivate them and move them in the direction that they would like to go. ${ }^{6}$

While full agreement on SDM excellence was less frequently associated with providers who took HealthChange, most providers felt that HealthChange influenced their patient interactions and site processes to some degree $(76.9 \%$ and $53.8 \%$, respectively). In addition, providers who took the training were less likely to rate their interactions with the highest score $(37 / 119=31.6 \%)$ when compared with providers who did not take the training $(82 / 178=47.4 \% ; \mathrm{p}<0.01)$. Provider training was not associated with patient ratings. Patients with providers who took the training did not rate their interactions as less favourable than patients with providers who did not take the training $(69 / 119=61.6 \%$ vs $110 / 178=64.7 \%$; $\mathrm{p}=0.876)$. This suggests that providers who took the training may be more discerning when judging their interactions with patients.

This work, however, may suffer from similar challenges as the train-the-trainer SDM-development activities completed previously in Europe that did not yield increased patient involvement in decision-making. ${ }^{24} 25$ In our study and that in Europe, providers perceive an impact of their training relating to the processual aspects 


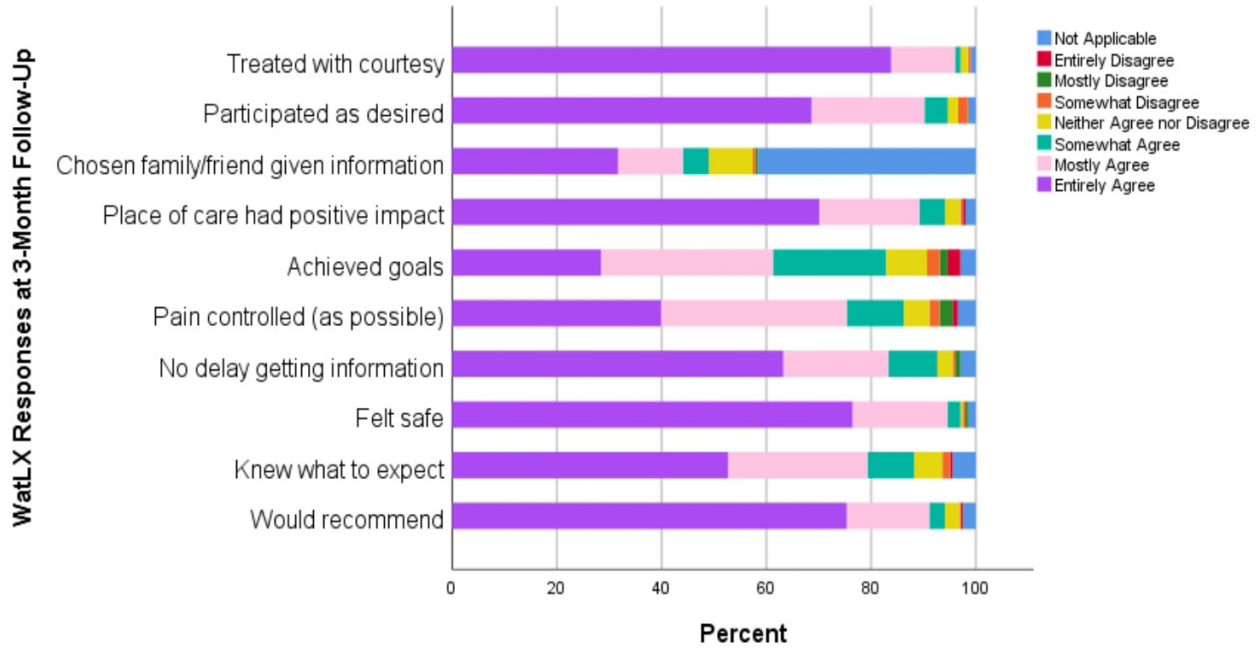

Figure 6 Patient ratings of experience on individual WatLX items.

of SDM, but in both cases a statistically significant positive impacts on SDM is not determined between those with training and those without. ${ }^{24}{ }^{25}$ More research is required to determine what facets of SDM and patient-centred communication training lead to tangible improvements in SDM experiences.

Most non-modifiable patient characteristics (including age) were not significantly associated with the quality of SDM or goal setting. Only total family income was associated with SDM experience. These findings corroborate the literature that SDM is a skill that can be taught and not an innate trait of an individual.$^{56}$ Total family income is a marker of socioeconomic status and relative vulnerability; it is not about capacity or education because education level was not associated with SDM experience. Further strategies and training are likely required to support providers and organisations in identifying, then approaching and empowering, more economically vulnerable patients in SDM.

The literature describes SDM, while highly relational (conceptually and practically), is influenced by contextual factors such as time and setting. ${ }^{185758}$ Our findings do not quantify further details on the contextual factors. Our regression results suggested that geographical settings do vary on quality of SDM. Non-metropolitan areas, which often have more resources but busier clinics, had lower likelihoods of high-quality SDM experiences compared with rural and regional settings. Geographical areas did vary statistically on types of rehabilitation providers, months patient and provider knew each other, and provider training in patient-centred principles. Finally, as different disciplines seem to have varying success with SDM, there may be an opportunity to promote greater transdisciplinary learning, practice and sharing in community-rehabilitation sites. This would support the development of a community of practice, which would also sustain learnings from person-centred training (eg, HealthChange) through ongoing discussion.
Based on participant demographics, these findings confidently apply to diverse community rehabilitation settings across Alberta. The patient population was fairly distributed among different family incomes, insurance access and employment. These findings were not as highly represented from patients originating from rural communities, ethnocultural communities and less-educated populations (ie, less than high school).

Participating providers were mostly fairly experienced. The findings apply to hospital-based and communitybased settings. These findings may not apply to new graduates or providers trained outside of Canada. Most providers represented two rehabilitation disciplines: occupational therapy and physiotherapy. While several other disciplines were present to a lesser degree, it may be useful to examine these research questions where these other disciplines are more populous.

\section{Limitations}

We recognise several study limitations. First, we tried to minimise recall (memory) bias by placing a 24 hours limit on participants to complete surveys, so the appointment is fresh in their minds. We recognise that patients may not have completed the survey on time with take-home packages since it was outside the supervision of researchers and recruiters.

Second, we tried to lessen the risk of loss at 3-month follow-up using several tactics from Dillman et al. ${ }^{59}$ These tactics included allowing participant preference to dictate the form of follow-up (email or paper); using a mix of email and phone reminders both pre-T1 and post-T1. We lost about $40 \%$ of patients at T1. Demographically, the patient-participants at recruitment and follow-up did not differ significantly on any patient characteristics.

Third, phase-1 learnings suggested that there may be a selection bias and non-response bias. Patients with extreme experiences (either good or bad) could have been more interested in participation, which could differ significantly from the general patient-population 
experience. It was unlikely, given the difficulty in patient recruitment generally, to recruit non-responders to participate in a non-responder survey. This study prioritised significant recruitment using convenience sampling to lessen the influence of these biases.

Fourth, there may have been a Hawthorne effect on providers wherein their knowledge of a study assessing their communication altered their communicative behaviours. A previous feasibility study demonstrated that rehabilitation professionals were accustomed to being observed during practice given their own training, the multidisciplinary players and trainee presence at many sites. For patients, they would generally not know of the study until after their appointment, so their actions likely would not be influenced by reactive effects.

Fifth, there may have been acquiescence and social desirability bias whereby participants frequently endorsed positive statements and where participants wished to present themselves at their best, including being fully engaged in SDM. Historically, this has been shown to have a small but pervasive effect. To minimise this, we aimed to recruit until a high survey sample size and diversity of population were recruited.

Sixth, for feasibility, survey tools were used differently from their original validation process. The WatLX was completed 3 months after recruitment which corresponded differently across patients' rehabilitation journey; not all patients completed the WatLX within the 2 weeks after care ended. Most patients stated at recruitment that they were neither at the first nor last appointment. Only $4.4 \%$ of patients were on their last appointment at recruitment. The most egregious difference in WatLX completion (ie, 3 months after last appointment) was only possible for a rarity of participants. The gains made in data collection compared with the feasibility study suggest that this compromise in data collection was worthwhile. The resonance and corroboration of findings across methods and studies confirm that the tools remained valid.

Seventh, we cannot guarantee that ASK-MI survey completion was based on assessments of the recruitmentdate appointment only rather than on the totality of experience with that patient, provider or clinic. Many participating patient comments in the ASK-MI referred to the entirety of their rehabilitation care. Patients may have felt that there was commonality or consistency in interactions across appointments, so it was then appropriate to assess SDM across the rehabilitation journey. Further research is required to understand when and how patients judge SDM in rehabilitation along the different points in the rehabilitation journey.

\section{CONCLUSIONS}

While we recognise several study limitations, we believe our forethought and planning to consider and address these limits ensures the methodological rigour of this study. This study complements our qualitative findings $s^{60}$ that SDM is complex not monolithic in community rehabilitation. There is room to improve on patient and provider practices of SDM and collaborative goal setting in these settings, and we offer strategies such as further person-centred training, enhancing privacy during appointments and building transdisciplinary communities of practice around how rehabilitation providers can approach SDM with patients. Further research is required to determine whether novel scoring of the ASK-MI influences SDM prevalence, and to ascertain which tactics will identify and redress the vulnerability of low-family-income patients to advance SDM for this vulnerable group. This study suggests that SDM experience and goal setting are not associated with longitudinal perceptions of rehabilitation experience and treatment goals being met, using a tool with high ceiling effects. We recommend more research into strategies that advance highly functional goal setting with patients, and to re-examine these relationships with tools without (or with less prominent) ceiling effects.

Twitter Kiran Pohar Manhas @kiran.manhas2

Acknowledgements The authors acknowledge their participants, both patient and provider, at the participating sites. They acknowledge the site managers, therapy assistants, clerks and non-participating providers at each site who were pivotal to recruitment and supporting the study more broadly. They particularly thank Jean Miller and Sylvia Teare, who are Patient and Community Engagement Researchers and who acted as patient consultants on this project. They thank the provincial and regional leadership at Alberta Health Services, including Lisa Warner and Elaine Finseth, who were (and continue to be) champions of this work. They also acknowledge Momentum Health, and their leadership Shaun Macauley, who were pivotal to the realisation of this work.

Contributors KPM helped contribute to the study's conceptualisation and design. KPM implemented the study methodology, managed resources and developed all manuscript drafts. KO helped contribute to the study's conceptualisation and provided ongoing supervision in close collaboration with the other senior authors (SV, TW) regarding its methods, conduct, analysis and manuscript development. KC helped contribute to the study's operationalisation; provided ongoing support on conduct, analysis and manuscript development; and reviewed and edited this manuscript. PF helped contribute to data analysis during study implementation, final write-up of the organisational report, and this manuscript's analyses and results and discussion write-up; and reviewed and edited this manuscript. SV helped contribute to the study's conceptualisation and provided ongoing supervision in close collaboration with the other senior authors (KO, TW) regarding its methods, conduct, analysis and manuscript development. TW helped contribute to the study's conceptualisation and provided ongoing supervision in close collaboration with the other senior authors (KO, SV) regarding its methods, conduct, analysis and manuscript development.

Funding This work was supported by the Canadian Institutes for Health Research Health System Impact Fellowship (Code 201705HI7-388576-170744, 2017). Supplemental funding was provided by the Strategic Clinical Networks and Research Challenge portfolios at Alberta Health Services.

Competing interests None declared.

Patient and public involvement Patients and/or the public were involved in the design, or conduct, or reporting, or dissemination plans of this research. Refer to the Methods section for further details.

Patient consent for publication Not required.

Ethics approval Research ethics board approval was secured for this study from the Conjoint Health Research Ethics Board, University of Calgary.

Provenance and peer review Not commissioned; externally peer reviewed.

Data availability statement De-identified data are available upon reasonable request for the data wherein patients consented to future data sharing. The deidentified data are currently being prepared for deposit in a secure data repository for data sharing upon application. 
Open access This is an open access article distributed in accordance with the Creative Commons Attribution Non Commercial (CC BY-NC 4.0) license, which permits others to distribute, remix, adapt, build upon this work non-commercially, and license their derivative works on different terms, provided the original work is properly cited, appropriate credit is given, any changes made indicated, and the use is non-commercial. See: http://creativecommons.org/licenses/by-nc/4.0/.

ORCID iD

Kiran Pohar Manhas http://orcid.org/0000-0002-1486-2387

\section{REFERENCES}

1 Department of Health. Liberating the NHS: no decision about me without me. London, 2010. Available: https://www.gov.uk/ government/uploads/system/uploads/attachment_data/file/ 216980/Liberating-the-NHS-No-decision-about-me-without-meGovernment-response.pdf

2 Pope TM. Certified patient decision AIDS: solving persistent problems with informed consent law. J Law Med Ethics 2017;45:12-40.

3 Canadian Institutes of Health Research. Strategy for patient-oriented research (SPOR, 2019.

4 Alberta Innovates. The Alberta SPOR support unit, 2017. Available: https://albertainnovates.ca/our-health-innovation-focus/the-albertaspor-support-unit/ [Accessed 14 Mar 2017].

5 Advisory Panel on Healthcare Innovation. Unleashing innovation: excellent healthcare for Canada, 2015. Available: http://www. healthycanadians.gc.ca/publications/health-system-systeme-sante/ report-healthcare-innovation-rapport-soins/alt/report-healthcareinnovation-rapport-soins-eng.pdf

6 AHS Provincial Rehabilitation Forum. Rehabilitation strategic plan 2016-2019.Edmonton, AB, 2016. Available: https://www.alberta-tr. org/media/46444/ahs-rehabilitation-strategic-plan-2016.pdf

7 Alberta Health Services. Alberta Health Services Health Plan \& Business Plan 2016-17. Edmonton, AB, 2016. Available: https:// www.albertahealthservices.ca/assets/about/publications/ahs-pubhealth-business-plan.pdf

8 O'Connor AM, Wennberg JE, Legare F, et al. Toward the 'tipping point': Decision aids and informed patient choice. Health Aff 2007;26:716-25

9 Légaré F, Witteman HO. Shared decision making: examining key elements and barriers to adoption into routine clinical practice. Health Aff 2013;32:276-84.

10 Elwyn G, Frosch DL, Kobrin S. Implementing shared decisionmaking: consider all the consequences. Implementation $\mathrm{Sci}$ 2015;11:114.

11 Godolphin W. Shared decision-making. Healthc Q 2009;12 Spec No Patient:e186-90.

12 Shay LA, Lafata JE. Where is the evidence? A systematic review of shared decision making and patient outcomes. Med Decis Making 2015;35:114-31.

13 Saheb Kashaf M, McGill ET, Berger ZD. Shared decision-making and outcomes in type 2 diabetes: a systematic review and meta-analysis. Patient Educ Couns 2017;100:2159-71.

14 Flynn D, Knoedler MA, Hess EP, et al. Engaging patients in health care decisions in the emergency department through shared decision-making: a systematic review. Acad Emerg Med 2012;19:959-67.

15 Kew KM, Malik P, Aniruddhan K, et al. Shared decision-making for people with asthma. Cochrane Database Syst Rev 2017;101.

16 Coxeter P, Del Mar CB, McGregor L, et al. Interventions to facilitate shared decision making to address antibiotic use for acute respiratory infections in primary care. Cochrane Database Syst Rev 2015:CD010907.

17 Kashaf MS, McGill E. Does shared decision making in cancer treatment improve quality of life? A systematic literature review. Med Decis Making 2015;35:1037-48.

18 Légaré F, Ratté S, Gravel K, et al. Barriers and facilitators to implementing shared decision-making in clinical practice: update of a systematic review of health professionals' perceptions. Patient Educ Couns 2008;73:526-35.

19 Joseph-Williams N, Lloyd A, Edwards A, et al. Implementing shared decision making in the NHS: lessons from the magic programme. BMJ 2017;357:j1744.

20 Makoul G, Clayman ML. An integrative model of shared decision making in medical encounters. Patient Educ Couns 2006;60:301-12.

21 Rose A, Rosewilliam S, Soundy A. Shared decision making within goal setting in rehabilitation settings: a systematic review. Patient Educ Couns 2017;100:65-75.
22 Wade DT. Goal setting in rehabilitation: an overview of what, why and how. Clin Rehabil 2009;23:291-5.

23 Körner M, Ehrhardt H, Steger A-K. Designing an interprofessional training program for shared decision making. $J$ Interprof Care 2013;27:146-54.

24 Körner M, Ehrhardt H, Steger A-K, et al. Interprofessional SDM trainthe-trainer program "Fit for SDM": provider satisfaction and impact on participation. Patient Educ Couns 2012;89:122-8.

25 Koerner M, Wirtz M, Michaelis M, et al. A multicentre clusterrandomized controlled study to evaluate a train-the-trainer programme for implementing internal and external participation in medical rehabilitation. Clin Rehabil 2014;28:20-35.

26 Quaschning K, Körner M, Wirtz M. Analyzing the effects of shared decision-making, empathy and team interaction on patient satisfaction and treatment acceptance in medical rehabilitation using a structural equation modeling approach. Patient Educ Couns 2013;91:167-75.

27 Plewnia A, Bengel J, Körner M. Patient-centeredness and its impact on patient satisfaction and treatment outcomes in medical rehabilitation. Patient Educ Couns 2016;99:99.

28 Grim K, Rosenberg D, Svedberg P, et al. Development and usability testing of a web-based decision support for users and health professionals in psychiatric services. Psychiatr Rehabil J 2017;40:293-302.

29 Tomori K, Uezu S, Kinjo S, et al. Utilization of the iPad application: aid for decision-making in occupation choice. Occup Ther Int 2012;19:88-97

30 Delany C, Galvin J. Ethics and shared decision-making in paediatric occupational therapy practice. Dev Neurorehabil 2014;17:347-54.

31 Karol RL. Team models in neurorehabilitation: structure, function, and culture change. NeuroRehabilitation 2014;34:655-69.

32 Ness O, Borg M, Semb R, et al. "Walking alongside:" collaborative practices in mental health and substance use care. Int $J$ Ment Health Syst 2014;8:55

33 McMurray J, McNeil H, Lafortune C, et al. Measuring patients experience of rehabilitation services across the care continuum. Part II: key dimensions. Arch Phys Med Rehabil 2016;97:121-30.

34 McMurray J, McNeil H, Lafortune C, et al. Measuring patients' experience of rehabilitation services across the care continuum. Part I: a systematic review of the literature. Arch Phys Med Rehabil 2016;97:104-20.

35 Scholl I, Koelewijn-van Loon M, Sepucha K, et al. Measurement of shared decision making - a review of instruments. Z Evid Fortbild Qual Gesundhwes 2011;105:313-24.

36 Scholl I, Kriston L, Dirmaier J, et al. Comparing the nine-item Shared Decision-Making Questionnaire to the OPTION Scale - an attempt to establish convergent validity. Health Expect 2015;18:137-50.

37 Barr PJ, Elwyn G. Measurement challenges in shared decision making: putting the 'patient' in patient-reported measures. Health Expect 2016;19:993-1001

38 Bouniols $\mathrm{N}$, Leclère $\mathrm{B}$, Moret $\mathrm{L}$. Evaluating the quality of shared decision making during the patient-carer encounter: a systematic review of tools. BMC Res Notes 2016;9:382.

39 Légaré $F$, Moher D, Elwyn G, et al. Instruments to assess the perception of physicians in the decision-making process of specific clinical encounters: a systematic review. BMC Med Inform Decis Mak 2007;7:30.

40 Stubenrouch FE, Pieterse AH, Falkenberg R, et al. OPTION(5) versus OPTION(12) instruments to appreciate the extent to which healthcare providers involve patients in decision-making. Patient Educ Couns 2016;99:1062-8.

41 Barr PJ, O'Malley AJ, Tsulukidze M, et al. The psychometric properties of Observer OPTION(5), an observer measure of shared decision making. Patient Educ Couns 2015;98:970-6.

42 Manhas KP, Olson K, Churchill K, et al. Experiences of shared decision-making in community rehabilitation: a focused ethnography. BMC Health Serv Res 2020;20:329.

43 Olson K. Development of the Alberta shared decision-making measurement instrument.

44 Speziale HJS, Carpenter DR. Qualitative Research in Nursing: Advancing the Humanistic Imperative. Philadelphia, PA: Lippincott, 2007

45 Spradley J. The Ethnographic Interview. Belmont, CA: Wadsworth, 1979.

46 Cruz EV, Higginbottom G. The use of focused ethnography in nursing research. Nurse Res 2013:20:36-43.

47 Higginbottom G, Pillay JJ, Boadu NY. Guidance on performing focused Ethnographies with an emphasis on healthcare research. Qual Rep 2013;18:1-6.

48 HealthChange Associates, Alberta Health Services. Person-Centred practice using HealthChange methodology. Edmonton, AB, 2017. 
49 Mcmurray J, McNeil H, Eilliott J. WatLX: A system-wide patient experience measure for rehabilitation. In: Canadian Association for Health Systems and Policy Research 2016 Conference: A Learning Healthcare System. Toronto, ON, 2016.

50 Alberta Health Services. Rehabilitation conceptual framework. Edmonton, AB, 2012.

51 Howell DC. The analysis of missing data. In: Outhwaite W, Turner S, eds. Handbook of social science methodology. London, UK: SAGE, 2008. http://www.uvm.edu/ dhowell/StatPages/Missing_Data/ MissingDataFinal.pdf

52 Janssen MF, Pickard AS, Golicki D, et al. Measurement properties of the EQ-5D-5L compared to the EQ-5D-3L across eight patient groups: a multi-country study. Qual Life Res 2013;22:1717-27.

53 Gale J, Skouteris H. Health coaching: Facilitating health behaviour change for chronic condition prevention and self-management. In: Caltabiano M, Ricciardelli L, eds. Handbook of Applied Topics in Health Psychology. Wiley-Blackwell, 2013.

54 Devet HCW, Terwee CB, Mokkink LB, et al. Measurement in Medicine. Cambridge, UK: Cambridge University Press, 2011.
55 Pritchard-Wiart L, Thompson-Hodgetts S, McKillop AB. A review of goal setting theories relevant to goal setting in paediatric rehabilitation. Clin Rehabil 2019;33:1515-26.

56 Légaré $F$, Thompson-Leduc $P$. Twelve myths about shared decision making. Patient Educ Couns 2014;96:281-6.

57 Elwyn G, Scholl I, Tietbohl C, et al. "Many miles to go ...": a systematic review of the implementation of patient decision support interventions into routine clinical practice. BMC Med Inform Decis Mak 2013;13 Suppl 2:S14.

58 Joseph-Williams N, Elwyn G, Edwards A. Knowledge is not power for patients: a systematic review and thematic synthesis of patientreported barriers and facilitators to shared decision making. Patient Educ Couns 2014;94:291-309.

59 Dillman D, Smyth J. Internet, mail and mixed-mode surveys: The tailored design method. Hoboken, NJ: John Wiley \& Sons, Ltd, 2009.

60 Manhas KP, Olson K, Churchill K. Shared decision-making experiences in community rehabilitation in Alberta, Canada. BMC Health Services Research 2020;20:329. 